\title{
Long-term effects on the health of men engaged in the manufacture of tolylene di-isocyanate
}

\author{
W. G. F. ADAMS \\ Imperial Chemical Industries Ltd., Thornton, Blackpool
}

\begin{abstract}
Adams, W. G. F. (1975). British Journal of Industrial Medicine, 32, 72-78. Long-term effects on the health of men engaged in the manufacture of tolylene di-isocyanate. A prospective study of workers engaged in the manufacture of tolylene di-isocyanate (TDI) was carried out over nine years. The study was in two parts: (1) assessment of the symptoms and ventilatory function of men working on the plants who did not complain of respiratory symptoms; (2) assessment of the long-term effects in men who were removed from the plants because of respiratory symptoms. Use of the MRC Questionnaire on Respiratory Symptoms in a group of 76 TDI workers showed no significant differences in symptoms compared with 76 control subjects.

Annual lung function tests were carried out on 180 asymptomatic men with possible exposure to TDI. The relationship of the forced expiratory volume in 1 second (FEV 1$)$ and forced vital capacity (FVC) to the height, age, and duration of exposure was examined by linear regression analysis. The equations formulated did not differ significantly from those calculated for non-TDI exposed subjects. Thus exposure to very small concentrations of TDI does not necessarily cause symptoms or a drop in ventilatory capacity.

Forty-six TDI workers who had developed symptoms reported more long-term symptoms than a comparable number of controls. The difference was significant at the $1 \%$ level.

Ventilation test records of 61 TDI workers who had developed symptoms were available since it was possible to use the records of men who had left the company. The lung function of this group was matched against predicted figures obtained from a control group of 608 subjects living in the same area as the exposed group but not exposed to TDI. It was found that the FEV 1 of the affected men was on average $267 \mathrm{ml}$ lower than predicted, and the FVC $269 \mathrm{ml}$ lower.

These findings are confirmed by examination of the individual records of a further 20 men.
\end{abstract}

Although the short-term effects of tolylene diisocyanate (TDI) are well known, there is less information on its long-term effects. This paper reports experience of men with and without symptoms working on tolylene di-isocyanate plants.

Isocyanates form one of the principal reagents used in the manufacture of polyurethane plastics. Of these TDI is the most hazardous, having a TLV of $0.02 \mathrm{ppm}$. It apparently acts as a respiratory sensitizing agent, giving rise to asthma-like symptoms which recur on exposure to very small concentrations (Williamson, 1964), and exposure to higher concentrations causes respiratory tract irritation. Reinl (1953) described a man who developed asthma while working with TDI in 1944, necessitating three months off work. $X$-ray examination of his lungs in 1948 showed chronic emphysema and at necropsy in 1952, following death from congestive heart failure, both lungs were found to be grossly emphysematous. Maxon (1963) followed up four 
men who had become sensitized to TDI; one showed radiographic changes suggesting emphysema, and two had a reduced FEV 1 . McKerrow, Davies, and Parry Jones (1970) followed up 36 firemen who had been exposed to high concentrations of TDI on a single occasion while fighting a fire. Although it was decided that any disturbance of ventilatory function was probably transitory, four men were producing sputum six months after the fire, while another three who had suffered from simple bronchitis in the past claimed that their symptoms were worse. The same authors also examined a group of 22 TDI workers who had to be permanently removed from contact with TDI because of symptoms. Eighteen of these men had no sputum before they experienced acute symptoms following exposure to TDI. Two of them subsequently developed simple chronic bronchitis (Medical Research Council Questionnaire on Respiratory Symptoms, 1966) and a further seven developed symptoms of chronic mucopurulent bronchitis (persistent sputum with one or more attacks of purulent chest illness resulting in absence from work for at least one week) over a two and a half year period following exposure. The $F E V_{1}$ for the group was $400 \mathrm{ml}$ lower than the average for a similar group not exposed to TDI.

Peters, Murphy, Pagnotto, and van Ganse (1968) and Peters, Murphy, Pagnotto, and Whittenberger (1970) studied symptomless men working in a TDI plant. In a group of 22 men working in atmospheric levels of TDI said to be below $0.012 \mathrm{ppm}$, the average fall in the $\mathrm{FEV}_{1}$ was $110 \mathrm{ml}$ against a predicted fall of $25-47 \mathrm{ml}$ per year. None of the men was obviously sensitized. Hill (1970), on the other hand, found no significant reduction in lung function in men working with TDI, but there was an increased incidence of bronchitis.

\section{Population and methods}

The population studied in this survey was employed in two TDI-manufacturing plants, one of which opened in 1961 and the other in 1965. This explains the fairly heavy recruiting carried out in 1964 (Table 1).

Approximately 250 measurements a week of TDI concentration are taken at the points in the plant where free TDI might be expected to be found. The Marcali method of testing is used, which depends on air being sucked through dilute hydrochloric acid solution in which TDI is hydrolysed to tolylene diamine. It is then diazotized and coupled with N-(1-naphthylethylene diamine) to give a purple coloured solution. The depth of colour can be measured either by an instrument or by visual comparison with inorganic colour standards (Marcali, 1957).

Table 2 shows the concentrations found between 1961 and 1970. A number of the tests giving results above the TLV were taken when high concentrations might be expected, such as breaking into a line, repairing a pump, etc. The first part of the study is concerned with men working in TDI-manufacturing plants for periods of one to 11 years without adverse effect on their health. Each plant employs approximately 80 people, although other personnel such as maintenance men spend varying amounts of time on the plant. There has been some turnover, so that a total of 565 men have been employed for some period from 1961 to 1972 . Since $1964 \mathrm{FEV}_{1}$ and FVC have been measured annually in all men, using a Garthur Vitalograph, and results are available for 180 men. All the examinations have been made by the author on the same afternoon each week between the hours of $2 \mathrm{pm}$ and $3 \mathrm{pm}$, and as far as possible each individual is seen in the same month as in the previous year. The Medical Research Council Questionnaire on Respiratory Symptoms (1966) was brought into use in 1970 and has been used annually since. Results from the questionnaire for 76 men, all of whom are still employed on the plants, were compared with those from 76 controls who had no contact with TDI but did similar work at a nearby plant owned by the same company. Controls were selected from employees attending their works surgery for minor injuries and were age-matched to the TDI group.

The second part of the study is concerned with longterm effects in men who had to be removed from the TDI plants because of symptoms. The symptoms were mainly bronchospasm resembling asthma, varying from a mild attack in the early stages to fairly severe bronchospasm if the man was allowed to remain in contact with TDI. There was usually dyspnoea on effort also. The acute stage following exposure may last for a week or two but usually gradually passes off after removal from further contact with TDI. The onset of symptoms was not related to previous respiratory infection, the presence of which did not appear to affect a man's susceptibility. Although prolonged high exposure or one heavy contamination will usually eventually lead to sensitization, the majority of cases arose from exposure to levels of TDI around the TLV of $0.02 \mathrm{ppm}$. The duration of such exposure was usually short (Table 3 ). The methods used to assess these men were also the MRC questionnaire, and $\mathrm{FEV}_{1}$ and FVC. Information on symptoms was available in 46 subjects who were compared with a control group of 46 age-matched non-TDI workers, and ventilation test results were available for 61 subjects. The difference in numbers of subjects for the two types of investigation is because retrospective data of lung function tests were available in the records of men who had left the works, but it was not possible to contact them to answer the MRC questionnaire. Men in the affected group have been assessed annually in the same way as the men currently working on the TDI plants. FEV 1 and FVC readings taken during the acute phase have not been used, but readings made six months or more after removal from contact with TDI have been analysed. Lowe et al. (1968) showed that two large populations living only 20 miles apart showed differences in the FEV 1 and FVC of about $5 \%$. It was decided, therefore, to establish predicted values for the subjects living in the area of the plants involved in the present study by measuring the $\mathrm{FEV}_{1}$ and FVC of 608 control subjects who had no contact with TDI. A multiple linear regression computer program was used to analyse the results. The equations obtained were: 
TABLE 1

Men Removed from the TDI Plants Since Start-up in 1961

\begin{tabular}{|c|c|c|c|c|c|c|c|c|c|c|c|c|c|c|c|c|}
\hline \multirow{3}{*}{ Year } & \multicolumn{16}{|c|}{ Year of work on TDI plant } \\
\hline & \multicolumn{4}{|c|}{1} & \multicolumn{4}{|c|}{2} & \multicolumn{4}{|c|}{3} & \multicolumn{4}{|c|}{4} \\
\hline & $a$ & $b$ & $c$ & $d$ & $a$ & $b$ & $c$ & $d$ & $a$ & $b$ & $c$ & $d$ & $a$ & $b$ & $c$ & $d$ \\
\hline $\begin{array}{c}\text { pre-1964 } \\
1964 \\
1965 \\
1966 \\
1967 \\
1968 \\
1969 \\
1970\end{array}$ & $\begin{array}{r}256 \\
118 \\
52 \\
34 \\
20 \\
17 \\
33 \\
35\end{array}$ & $\begin{array}{r}39 \\
19 \\
5 \\
5 \\
5 \\
3 \\
6 \\
2\end{array}$ & $\begin{array}{r}89 \\
4 \\
5 \\
4 \\
3 \\
2 \\
7 \\
1\end{array}$ & \begin{tabular}{|l|}
15 \\
$16 \cdot 8$ \\
$9 \cdot 6$ \\
$14 \cdot 7$ \\
25 \\
$17 \cdot 6$ \\
18 \\
$5 \cdot 7$
\end{tabular} & $\begin{array}{r}128 \\
95 \\
42 \\
25 \\
12 \\
12 \\
20 \\
32\end{array}$ & $\begin{array}{l}1 \\
6 \\
1 \\
1 \\
1 \\
0 \\
2 \\
1\end{array}$ & $\begin{array}{r}11 \\
8 \\
3 \\
2 \\
0 \\
1 \\
5 \\
4\end{array}$ & $\begin{array}{l}0 \cdot 8 \\
6 \\
2 \cdot 3 \\
4 \\
8 \cdot 3 \\
0 \\
10 \\
3 \cdot 1\end{array}$ & $\begin{array}{r}116 \\
81 \\
38 \\
22 \\
11 \\
11 \\
13 \\
27\end{array}$ & $\begin{array}{l}2 \\
3 \\
0 \\
2 \\
0 \\
1 \\
1 \\
1\end{array}$ & $\begin{array}{l}5 \\
4 \\
3 \\
1 \\
0 \\
0 \\
0 \\
0\end{array}$ & $\begin{array}{l}1 \cdot 7 \\
3 \cdot 7 \\
0 \\
9 \\
0 \\
9 \\
7 \cdot 6 \\
3 \cdot 7\end{array}$ & $\begin{array}{r}109 \\
74 \\
35 \\
19 \\
11 \\
10 \\
12\end{array}$ & $\begin{array}{l}0 \\
2 \\
0 \\
2 \\
0 \\
0 \\
0\end{array}$ & $\begin{array}{r}11 \\
4 \\
2 \\
1 \\
0 \\
0 \\
0\end{array}$ & 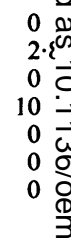 \\
\hline Total & 565 & 84 & & $14 \cdot 8$ & 366 & 13 & & $3 \cdot 5$ & 319 & 10 & & 3 & 270 & 4 & & \\
\hline
\end{tabular}

$a=$ No. of healthy men currently employed on the TDI plants at the beginning of period

$b=$ No. of men removed due to development of symptoms in that period

$c=$ No. of men leaving for non-medical reasons

$\mathrm{d}=$ Percentage affected $\left(\frac{\mathrm{b}}{\mathrm{a}} \times 100\right)$

Total $=$ Percentage of men developing symptoms for each year of exposure.

Predicted $\mathrm{FEV}_{1}(\mathrm{ml})=0.084$ (height in inches) -0.035 (age in years) -1.023

Predicted FVC $(\mathrm{ml})=0.125$ (height)-0.032 (age) -2.884

The standard deviation after allowing for height and age was $\mathbf{0 . 4 8 9}$ for $\mathrm{FEV}_{1}$ and $\mathbf{0 . 5 4 1}$ for the FVC.

In Table 4 these equations are compared with those obtained by Lowe et al. (1968) and Cotes (1968).

All equations are in close agreement, differing by no more than $7 \mathrm{ml}$ for age for the $\mathrm{FEV}_{1}$ and $5 \mathrm{ml}$ for the FVC. The $95 \%$ confidence interval for the true deterioration of the controls' $\mathrm{FEV}_{1}$ in the present study is from $32 \mathrm{ml}$ to $38 \mathrm{ml}$ per year. The corresponding confidence interval for the true deterioration of the FVC is from $28 \mathrm{ml}$ to 36 $\mathrm{ml}$ per year.

\section{Results}

The majority of men $(14.8 \%)$ removed from the plant because of development of respiratory symptoms were affected in their first year (Table 1); in the second and subsequent years only $1-3.5 \%$ of the remaining workmen developed symptoms.

\section{Healthy men working on TDI plants}

The results of the MRC questionnaire in 76 men and 76 control subjects from the nearby site are shown in Table 5.

Using the $\chi^{2}$ test there is no significant difference in symptoms between the men working on the TDI plant and the controls except in the case of wheezing, which was reported more frequently by control subjects. There was no significant difference in the
TABLE 2

Results of Tests for AtMospheric TDI DONE in the Plants SINCE 1961

\begin{tabular}{c|c|c}
\hline \multirow{2}{*}{ Year } & \multicolumn{2}{|c|}{$\%$ Tests above 0.02 ppm } \\
\cline { 2 - 3 } & Plant 1 & Plant 2 \\
\hline 1961 & - & - \\
1962 & $58^{1}$ & - \\
1963 & $7^{1}$ & - \\
1964 & $67^{1}$ & $13^{2}$ \\
1965 & 21 & 8 \\
1966 & 4 & 1 \\
1967 & 1 & 1 \\
1968 & 1 & 1 \\
1969 & 2 & 2 \\
1970 & 1 & \\
\hline
\end{tabular}

${ }^{1}$ These high readings were taken when the TLV was $0.05 \mathrm{ppm}$ and were usually between 0.05 and $0.1 \mathrm{ppm}$

2Plant started up

TABLE 3

PERIOD OF EMPLOYMENT PRIOR TO DEVELOPMENT OF SYMPTOMS IN 61 MEN

\begin{tabular}{c|c|c|c}
\hline $\begin{array}{c}\text { Less than } \\
1 \text { month }\end{array}$ & $\begin{array}{c}1-2 \\
\text { months }\end{array}$ & $\begin{array}{c}2-12 \\
\text { months }\end{array}$ & $\begin{array}{c}\text { More than } \\
12 \text { months }\end{array}$ \\
\hline $38 \%$ & $19 \%$ & $21 \%$ & $22 \%$ \\
\hline
\end{tabular}


ble 1 continued

\begin{tabular}{|c|c|c|c|c|c|c|c|c|c|c|c|c|c|c|c|c|c|c|c|}
\hline \multicolumn{20}{|c|}{ Year of work on TDI plant } \\
\hline \multicolumn{4}{|c|}{5} & \multicolumn{4}{|c|}{6} & \multicolumn{4}{|c|}{7} & \multicolumn{4}{|c|}{8} & \multicolumn{4}{|c|}{9} \\
\hline$a$ & $b$ & $c$ & $d$ & $a$ & $b$ & $c$ & $d$ & $a$ & $b$ & $c$ & $d$ & $a$ & $b$ & $c$ & $d$ & $a$ & $b$ & $c$ & $d$ \\
\hline $\begin{array}{l}98 \\
68 \\
33 \\
16 \\
11 \\
10\end{array}$ & $\begin{array}{l}2 \\
1 \\
0 \\
1 \\
0 \\
1\end{array}$ & $\begin{array}{r}11 \\
1 \\
3 \\
2 \\
0 \\
0\end{array}$ & $\begin{array}{l}2 \\
1 \cdot 4 \\
0 \\
6 \cdot 2 \\
0 \\
10\end{array}$ & $\begin{array}{l}85 \\
66 \\
30 \\
13 \\
11\end{array}$ & $\begin{array}{l}2 \\
0 \\
1 \\
0 \\
0\end{array}$ & $\begin{array}{l}5 \\
0 \\
0 \\
0 \\
0\end{array}$ & $\begin{array}{l}2 \cdot 3 \\
0 \\
3 \cdot 3 \\
0 \\
0\end{array}$ & $\begin{array}{l}78 \\
66 \\
29\end{array}$ & $\begin{array}{l}0 \\
2 \\
0\end{array}$ & $\begin{array}{l}3 \\
1 \\
0\end{array}$ & $\begin{array}{l}0 \\
3 \\
0\end{array}$ & $\begin{array}{l}75 \\
63\end{array}$ & $\begin{array}{l}1 \\
0\end{array}$ & $\begin{array}{l}0 \\
0\end{array}$ & $\begin{array}{l}1 \cdot 3 \\
0\end{array}$ & $\begin{array}{l}74 \\
63\end{array}$ & $\begin{array}{l}1 \\
1\end{array}$ & $\begin{array}{l}3 \\
1\end{array}$ & $\begin{array}{l}1 \cdot 3 \\
1 \cdot 5\end{array}$ \\
\hline 236 & 5 & & $2 \cdot 1$ & 205 & 3 & & $1 \cdot 4$ & 173 & 2 & & $1 \cdot 1$ & 138 & 1 & & 0.7 & 137 & 2 & & 1.4 \\
\hline
\end{tabular}

TABLE 4

Regression of Ventilatory Capacity on Height and Age

\begin{tabular}{|c|c|c|c|c|}
\hline & & Regression on height (in) and age (yr) & $S D$ & $\boldsymbol{R}$ \\
\hline 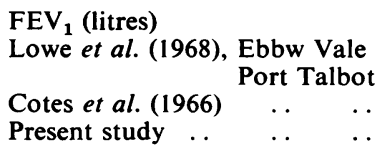 & $\begin{array}{l}\cdots \\
\cdots \\
\cdots \\
\cdots\end{array}$ & $\begin{array}{l}0.085 \mathrm{Ht}-0.041 \text { age }-0.667 \\
0.108 \mathrm{Ht}-0.042 \text { age }-2.037 \\
0.088 \mathrm{Ht}-0.033 \text { age }-1.12 \\
0.084 \mathrm{Ht}-0.035 \text { age }-1.023\end{array}$ & $\begin{array}{l}0.68 \\
0.59 \\
0.45 \\
0.49\end{array}$ & $\begin{array}{l}0.68 \\
0.72 \\
0.83 \\
0.65\end{array}$ \\
\hline 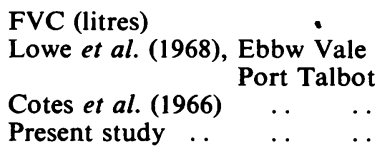 & $\begin{array}{l}\cdots \\
\cdots \\
\cdots \\
\cdots\end{array}$ & $\begin{array}{l}0.122 \mathrm{Ht}-0.035 \text { age }-2.429 \\
0.150 \mathrm{Ht}-0.037 \text { age }-4.106 \\
0.129 \mathrm{Ht}-0.032 \text { age }-3.02 \\
0.123 \mathrm{Ht}-0.032 \text { age }-2.884\end{array}$ & $\begin{array}{l}0.69 \\
0.63 \\
0.52 \\
0.54\end{array}$ & $\begin{array}{l}0.67 \\
0.71 \\
0.82 \\
0.69\end{array}$ \\
\hline
\end{tabular}

The author's results have been added to a table from Lowe et al. (1968).

TABLE 5

RESULT OF MRC QUESTIONNAIRE IN 76 MEN CURRENTLY WORKING ON TDI-MANUFACTURING Plants, AND 76 Controls

\begin{tabular}{|c|c|c|c|c|}
\hline & & $\begin{array}{l}T D I \\
\text { men }\end{array}$ & Controls & $\chi^{2}$ \\
\hline Asymptomatic & .. & 40 & 39 & 0.03 \\
\hline Frequent phlegm . & .. & 8 & 4 & $1 \cdot 45$ \\
\hline Cough in morning & .. & 17 & 13 & 0.66 \\
\hline Cough during day & . & 8 & 8 & \\
\hline Cough three months & or & & & \\
\hline more $\quad \ldots \quad \ldots$ & & 6 & 8 & 0.32 \\
\hline Cough symptoms combi & ned & 31 & 29 & $0 \cdot 11$ \\
\hline Breathless hurrying & $\ldots$ & 2 & 5 & $1 \cdot 35$ \\
\hline Breathless on level & 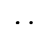 & 0 & 1 & 1.01 \\
\hline Wheezing occasionally & . & 19 & 19 & \\
\hline Wheezing frequently & .. & 1 & 9 & 6.85 \\
\hline
\end{tabular}

TABLE 6

SMOKING Habits of 76 Men CURRENTLY employed on the TDI Plants, aNd CONTROLS

\begin{tabular}{c|c|c|c|c|c}
\hline & \multicolumn{3}{|c|}{ No. of cigarettes per day } & \\
& 0 & $1-10$ & $11-20$ & $21-40$ & Pipes \\
\hline & & & & & \\
Men working on & & & 23 & 9 & 6 \\
TDI plants .. & 19 & 19 & 24 & 3 & 18 \\
Controls & 19 & 12 & 24 & & \\
\hline
\end{tabular}

age distribution of the two populations. There is a significant difference between TDI-exposed men and the controls in smoking habits $\left(\chi^{2}=10 \cdot 6\right)$ (Table 6) which appears to be caused mainly by pipe-smokers. 
If the pipe-smokers are excluded there is no significant difference between the groups $\left(\chi^{2}=3 \cdot 38\right)$.

\section{Ventilation tests}

The data from 180 men give 1100 data points from which a linear regression analysis has been carried out to examine the relationship of the $F E V_{1}$ and FVC to height, age, and duration of exposure. Duration of exposure is defined as the difference between the time the measurement was made and the time the men actually started on the plant. The equation for the FEV 1 before any significance tests were carried out was:

$\mathrm{FEV}_{1}(\mathrm{ml})=-1.005+0.086$ (height in inches)

-0.037 (age in years)

+0.002 (duration of exposure)

the standard errors associated with these coefficients being height 0.005 inches, age 0.002 years, duration of exposure 0.005 years. The residual standard deviation of this equation is 0.484 . A similar regression analysis was also carried 'out for the FVC, giving the following equation:

FVC $(\mathrm{ml})=-2.99+0.129$ (height in inches)

-0.039 (age in years)

+0.003 (duration of exposure),

the standard errors associated with these coefficients being height 0.006 inches, age 0.002 years, and duration of exposure 0.006 years. The residual standard deviation for this equation is $\mathbf{0 . 5 4 4}$.

In view of the standard errors of the exposure coefficients in both equations and the fact that the observed coefficients are positive, implying an increase of FEV 1 and FVC with exposure, it is clear that there is no evidence from these data that exposure accelerates the rate of decline. Omitting exposure from these equations leaves them almost unchanged:

$\mathrm{FEV}_{1}(\mathrm{ml})=+0.086$ (height in inches)

-0.037 (age in years) -1.020

FVC $(\mathrm{ml})=+0.129$ (height in inches)

-0.038 (age in years) -3.013 .

This does not materially change the residual standard deviations, which are now 0.485 and 0.545 respectively.

These equations are not significantly different from those calculated for non-TDI-exposed subjects. Although there is a fairly high correlation between age and duration of exposure, it is not sufficient to make this negative finding unreliable. It is concluded that duration of exposure to TDI has no effect on the FEV 1 or FVC.

Men removed from TDI plants because of symptoms Forty-six men who had had no further contact with TDI, for periods of between two and 11 years, were available for assessment. No significant difference was found in the smoking habits between the two groups $\left(\chi^{2}=2 \cdot 73\right)$. Because of the small number of men in the 21-40 cigarettes per day group, the 11-20 and 21-40 groups were combined (Table 7).

\section{TABLE 7}

SMOKING HABITS OF 46 MEN REMOVED FROM Isocyanates Plants beCause of Sensitization TO TDI, AND CONTROLS

\begin{tabular}{lc|c|c|c|c|c}
\hline & \multicolumn{3}{|c|}{ Number of cigarettes per day } & \multirow{2}{*}{ Pipes } \\
\cline { 3 - 6 } & & 0 & $1-10$ & $11-20$ & $21-40$ & \\
\hline TDI men &. & 11 & 10 & 18 & 3 & 0 \\
Controls & $\cdots$ & 12 & 7 & 16 & 2 & 9 \\
\hline
\end{tabular}

TDI-sensitized men suffered more respiratory symptoms than the control group at the $1 \%$ level of significance (Table 8). Breathlessness was more frequent in the TDI men at the $1 \%$ level, and wheezing occurred more frequently at the $5 \%$ significance level. The persistence of symptoms cannot be attributed to continuous exposure to TDI, so that it appears that long-term effects do occur in some subjects developing acute symptoms after TDI exposure.

TABLE 8

RESUlts OF MRC QUESTIÓNNAIRE IN 46 MEN REMOVED FROM ISOCYANATE PlaNTS BECAUSE OF SENSITIZATION TO TDI, AND 46 Controls

\begin{tabular}{l|c|c|c}
\hline & $\begin{array}{c}T D I \\
\text { men }\end{array}$ & Controls & $\chi^{2}$ \\
\hline $\begin{array}{c}\text { Asymptomatic . . . } \\
\text { Cough occurring most days } \\
\text { for as much as three } \\
\text { months of the year .. }\end{array}$ & 6 & 13 & 6.8 \\
$\begin{array}{c}\text { No. of men producing } \\
\text { phlegm for as much as } \\
\text { three months of the year }\end{array}$ & 10 & 3 & 3.22 \\
$\begin{array}{c}\text { No. of men breathless when } \\
\text { hurrying on level ground }\end{array}$ & 17 & $5^{1}$ & 7.23 \\
$\begin{array}{c}\text { No. of men breathless when } \\
\text { walking normally .. }\end{array}$ & 6 & 1 & 2.47 \\
$\begin{array}{c}\text { No. of men wheezing most } \\
\text { days or nights .. }\end{array}$ & 17 & $7^{2}$ & 4.57 \\
\hline
\end{tabular}

${ }^{1}$ Difference significant at $1 \%$ level

${ }^{2}$ Difference significant at $5 \%$ level

\section{Ventilation tests}

Data from 61 men were available for this study as it was possible to use the records of men who had left the company. At the time of testing, all these men had also been out of contact with TDI for a minimum of two and a maximum of 11 years. Although 
the majority of men become affected within the first year (Table 1), two men had worked on the plants for nine years before developing symptoms. Predicted $F E V_{1}$ and $F V C$ values were obtained for each $\mathrm{FEV}_{1}$ and FVC measurement recorded using the control equation given above. The average (actual $\mathrm{FEV}_{1}$ - predicted $\mathrm{FEV}_{1}$ ) was $-267 \mathrm{ml}$. For affected men as a whole, at the $5 \%$ probability level, the average value of (actual $\mathrm{FEV}_{1}$-predicted FEV 1 ) will lie between -198 and -336 (standard deviation 276). The average (actual FVC - predicted FVC) for all affected men was $-269 \mathrm{ml}$, and for affected men as a whole at the $5 \%$ probability level the average value of (actual FVC - predicted FVC) will lie between -195 and -343 (standard deviation 296).

Confirmation of these statistical results has been obtained from the records of 20 men for whom preemployment lung function data were available and who had been removed from the plants for between three and eight years because of sensitization to TDI. Eleven of these men were asymptomatic and 12 had no reduction in the FEV 1 or FVC below their pre-employment level. Of the remaining eight, six had a reduction in FEV 1 and FVC to between $\mathbf{9 0 \%}$ and $100 \%$ of the pre-employment figure, and two to between $80 \%$ and $90 \%$. In the few men with symptoms but no reduction in the FEV 1 or FVC, the symptoms were slight, consisting of intermittent cough with occasional wheezing at night. The men who had some reduction in their ventilatory capacity were more positive about their symptoms, complaining of dyspnoea on exertion, nocturnal dyspnoea, and tightness in the chest. This tends to support the statistical evidence that, although the reduction in lung function of sensitized men is slight, a fairly high proportion do appear to have long-term symptoms.

\section{Discussion}

Peters et al. (1970) demonstrated in men working in low concentrations of isocyanates (apparently below the TLV) that there was a persistent drop in the FEV 1 and FVC. This has not been found to be the case in the group studied here. This result may be criticized because the lack of reduction in lung function in this group could be due to an artefact arising from the removal from the plants of exposed men who had developed symptoms and because there is difficulty in constructing a valid control group for the selected TDI-exposed group.

Examination of Table 1, however, shows that 74 of the original 256 men are still employed on the TDI plants. Out of the number who left, 138 did so for non-medical reasons. From Table 1 it can be calculated that approximately $79 \%$ of the total number of men who have worked on the plants from one to 11 years show no signs of sensitization.
There is unfortunately no method whereby an exactly comparable group of controls can be obtained as the survivors on a TDI plant are selfselected but, as already pointed out, the controls are taken from the only possible comparable group, i.e., men living in the same area and doing a similar type of work on non-TDI chemical plants.

Although the criticisms are to a certain extent valid, it has been demonstrated that it is possible to work on a TDI plant in areas of low exposure to TDI (mainly below the present TLV of $0.02 \mathrm{ppm}$ ) without developing respiratory symptoms.

In the group who have had to be removed from the plants because of symptoms, the average $F_{E V}$ and FVC indicate a small but persistent drop below the predicted level. In the men for whom pre-employment ventilation tests are available this reduction in average $\mathrm{FEV}_{1}$ and $\mathrm{FVC}$ is caused by approximately $50 \%$ of the men (9 out of 20 ) being affected, the rest showing no reduction. The MRC questionnaire demonstrates that there is a significantly greater number of men suffering from chest symptoms of some description than in the control population. This part of the study demonstrates that sensitization to TDI can lead to long-term respiratory symptoms with slightly impaired ventilatory function. The cause of these effects has not as yet been established, but there is general agreement that allergic mechanisms are involved in at least a proportion of cases developing symptoms after exposure to TDI (Reinl, 1953; Swensson, Holmquist, and Lundgren, 1955; Woodbury, 1956; Scheel, Killens, and Josephson, 1964).

One of the puzzling features is the lack of consistency in the presentation of symptoms in that some men develop cough, dyspnoea, and bronchospasm within an hour of going onto the plant, while others do not develop symptoms until some hours after work, these coming on either while sitting in front of the fire or in bed. This situation is further complicated by the fact that the lag between exposure and the development of symptoms diminishes with duration of exposure, and eventually those men who initially did not develop symptoms until some hours after exposure develop them immediately following further contact. In the majority of cases the immediate symptoms are not due to primary irritation in that the man is unaware of the presence of TDI in the atmosphere and other men working in the immediate vicinity are unaffected. A possible explanation for this is the occurrence of type 1 and type 3 sensitivity reactions in the same person.

Further discussion on this is outside the scope of the present paper, and work on the immunological aspect of TDI-sensitization is at present going on. Those men in the present series who have persistent symptoms or diminished lung function tests are those in whom sensitization has taken place. 
Particular thanks are due to Mr. J. Derek Chamberlain, of Organics Division, ICI, for his advice and for his help in the statistical side of this paper.

My thanks are also due to Dr. K. S. Williamson, Principal Medical Officer, ICI, and Dr. A. Munn of Organics Division, ICI.

I also wish to thank Dr. P. D. Oldham, MRC Unit, Penarth, for his advice on statistical matters.

\section{References}

Cotes, J. E., Rossiter, C. E., Higgins, I. T. T., and Gilson, J. C. (1966). Average normal values for forced expiratory volume in white Caucasian males. British Medical Journal, 1, 1016.

Hill, R. N. (1970). A controlled study of workers handling organic diisocyanates. Proceedings of the Royal Society of Medicine, 63, 375.

Lowe, C. R., Pelmear, P. L., Campbell, H., Hitchens, R. A. N., Khosla, T., and King, T. C. (1968). Bronchitis in two integrated steel works. British Journal of Preventive and Social Medicine, 22, 1-11.

Marcali, K. (1957). Micro-determination of toluene diisocyanate in atmosphere. Analytical Chemistry, 29, 552.

Maxon, F. C. (1963). Respiratory irritation from toluene diisocyanate. Archives of Environmental Health, 8, 755-758.

McKerrow, C. B., Davies, H. J., and Parry Jones, D. A. (1970). Symptoms and lung function following acute and chronic exposure to tolylene diisocyanate. Proceedings of the Royal Society of Medicine, 63, 376-378.
Medical Research Council Questionnaire on Respiratory Symptoms (1966).

Peters, J. M., Murphy, R. L. H., Pagnotto, L. D., and van Ganse, W. F. (1968). Acute respiratory effects in workers exposed to low levels of toluene diisocyanate (TDI). Archives of Environmental Health, 16, 642-647. — , and Whittenberger, J. L. (1970). Respiratory impairment in workers exposed to "safe" levels of toluene diisocyanate (TDI). Archives of Environmental Health, 20, 364-367.

Reinl, W. (1953). Uber Erkrankungen beil der Verarbeitung von Kunststoffen auf der Basis der Polyurethane. (Sickness in fabricating plastics based on polyurethanes.) Zentralblatt für Arbeitsmedizin und Arbeitsschutz, 3, 103-107.

Scheel, L. D., Killens, R., and Josephson, A. (1964). Immunochemical aspects of toluene diisocyanate (TDI) toxicity. American Industrial Hygiene Association Journal, 25, 179-184.

Swensson, A., Holmquist, C. E., and Lundgren, K. D. (1955). Injury to the respiratory tract by isocyanates used in making lacquers. British Journal of Industrial Medicine, 12, 50-53.

Williamson, K. S. (1964). Studies of diisocyanate workers. Transactions of the Association of Industrial Medical Officers, 14, 81-88.

Woodbury, J. W. (1956). Asthmatic syndrome following exposure to tolylene diisocyanate. Industrial Medicine and Surgery, 25, 540-543.

Received for publication 31 December 1973. Accepted for publication 20 February 1974. 